\section{International Scientific Journal Theoretical \& Applied Science}

p-ISSN: 2308-4944 (print) e-ISSN: 2409-0085 (online)

Year: $2015 \quad$ Issue: $05 \quad$ Volume: 25

Published: $30.05 .2015 \quad$ http://T-Science.org

SECTION 6. Metallurgy and energy.
Bazartai Alimbayevich Alimbayev doctor of technical sciences, Professor of the department «Building materials and constructions» M.Kh. Dulaty Taraz State University, Kazakhstan

Bauyrzhan Zharkynbekovich Manapbayev candidate of technical sciences, associate professor of the Department of «Oil and gas engineering»

M.Kh. Dulaty Taraz State University, Kazakhstan jiboj@mail.ru

Adilet Dosmuhanbetovich Aliev Undergraduate degree in «Construction» M.Kh. Dulaty Taraz State University, Kazakhstan

\title{
FEATURES OF THE DEVELOPMENT OF CORROSION IN A METAL EXHAUST PIPES
}

\begin{abstract}
In work results of development of corrosion in a vertical exhaust metal pipe in height more than $+180 \mathrm{~m}$ which is on industrial object of the chemical industry, taking into account ferromagnetic properties of steel designs are presented.

Key words: corrosion of exhaust pipes, water film, molecules of water vapor, dissociation, ferromagnetic domains, Lorentz force.

Language: Russian

Citation: Alimbayev BA, Manapbayev BZ, Aliev AD (2015) FEATURES OF THE DEVELOPMENT OF CORROSION IN A METAL EXHAUST PIPES. ISJ Theoretical \& Applied Science 05 (25): 140-143.

Soi: http://s-o-i.org/1.1/TAS*05(25)26 Doi: crossef http://dx.doi.org/10.15863/TAS.2015.05.25.26

\section{ОСОБЕННОСТИ РАЗВИТИЯ КОРРОЗИИ В МЕТАЛЛИЧЕСКИХ ВЫТЯЖНЫХ ТРУБАХ}

Аннотация: В работе представлены результаты развития коррозии в вертикальной вытяжной металлической трубе высотой более +180 м, которая находится на производственном объекте химической промышленности, с учетом ферромагнитных свойств стальных конструкиий.

Ключевые слова: коррозия вытяжных труб, пленка влаги, молекуль водяного пара, диссоцииация, ферромагнитные домены, сила Лоренияа.
\end{abstract}

В сумме убытки от коррозии металлов и затраты на защиту в промышленно развитых странах достигают 4\% национального дохода и более. Большинство потерь от коррозии металлов приходится на атмосферную коррозию. Она наиболее распространенный вид коррозии, ее проявления настолько многочисленны и разнообразны, что совершенствование методов борьбы с ней не утрачивает своей актуальности.

Известно, что механизм развития коррозии играет важную роль при разработке способов и методов защиты от коррозии стальных конструкций. Учет ферромагнитных свойств стальных конструкций дает возможность пересмотреть механизм развития коррозии и предложить более эффективные методы защиты от коррозии [1-7].

По механизму протекания атмосферная коррозия является электрохимическим процессом. Главным фактором, определяющим интенсивность атмосферного коррозионного износа, является относительная влажность.

Процесс атмосферной коррозии возникает и развивается лишь в том случае, если на поверхности металла присутствует пленка влаги определенной толщины, приобретающая свойства электролита. Продолжительность развития коррозионного процесса и количество металла, превратившегося в продукты коррозии, зависит от длительности пребывания пленки электролита на поверхности металла. Чем дольше не высыхает пленка, образовавшаяся на металле, или чем чаще она возобновляется, тем дольше протекает процесс коррозии, следовательно, при всех прочих равных условиях тем большему коррозионному разрушению подвергается металл. В свете этого интересен механизм диссоциации водяного пара и влияние его на коррозию. 
При движении вверх от места парообразования молекулы водяного пара за счет трения и ударов об атмосферные смеси газов, в которой находятся во взвешенном состоянии жидкие и твердые частички подвергаются диссоциации и разделяются на ионы $\mathrm{H}^{+}$и $\mathrm{OH}^{-}$. Далее большинство ионов соединяются к пленке влаги на элементах металлических конструкций, покрывающие разрушенные участки их доменной структуры по механизму [8].

Ион $\mathrm{H}^{+}$«потерянный» молекулой водяного пара присоединяется к другой молекуле на пленке влаги на поверхности элемента стальной конструкции, образуя ион гидроксония $\mathrm{H}_{3} \mathrm{O}^{+}$, и реакция диссоциации пленки влаги записывается так:

$$
\mathrm{H}_{2} \mathrm{O}+\mathrm{H}_{2} \mathrm{O} \leftrightarrow \mathrm{H}_{3} \mathrm{O}^{+}+\mathrm{OH}^{-}
$$

Благодаря способности иона $\mathrm{H}^{+}$ «перескакивать» с одной молекулы на другую, ионы $\mathrm{H}_{3} \mathrm{O}^{+}$и $\mathrm{OH}^{-}$значительно более подвижны других одновалентных ионов. Аномальные подвижности ионов $\mathrm{H}_{3} \mathrm{O}^{+}$и $\mathrm{OH}^{-}$в пленке воды являются также следствием наличия водородных связей между молекулами. Эти связи способствуют быстрому переносу ионов $\mathrm{H}^{+}$. Например, один из протонов иона $\mathrm{H}_{3} \mathrm{O}^{+}$может перемещаться вдоль водородной связи скачками [9]. Сходным образом протон молекулы воды может двигаться вдоль водородной связи, взаимодействуя с ионом $\mathrm{OH}^{-}$.

Оба процесса вызывают миграцию электрического заряда, а при наличии приложенного поля приводят к появлению электрического тока. Это в свою очередь приводит к развитию электрохимической коррозии элементов металлических конструкций по механизму [8]. То есть на ионы $\mathrm{H}^{+}$и $\mathrm{OH}^{-}$в магнитном поле, созданном между разделенными частями ферромагнитных доменов элементов металлических конструкций, будет действовать сила Лоренца. Эти ионы по направлению силы Лоренца будут притягиваться к разрушенным участкам металла, как к полюсам магнита. После прохождения физического процесса начинается химическая реакция. В результате реакции ионы $\mathrm{H}^{+}$восстанавливаются и абсорбируются разрушенным участком металла или уходят в атмосферу в виде газа, а ионы $\mathrm{OH}^{-}$образуют гидроксид железа. В дальнейшем, пленка из гидроксида железа (II) $\mathrm{Fe}(\mathrm{OH})_{2}$ и гидроксида железа (III) $\mathrm{Fe}(\mathrm{OH})_{3}$ наполняют образовавшиеся трещины разрушенных участков металла, что приводит к замедлению или завершению процесса атмосферной коррозии на поверхностях металлических конструкций.

На вертикальных вытяжных металлических трубах, используемых в промышленных объектах, атмосферная коррозия развивается в зависимости от многих факторов. Основные из них это - состав выбрасываемых газов из вытяжных труб (пар, выхлопы, пыль, дым и т.п.), температура и влажность окружающей среды. Интересен и тот факт, что на скорость развития коррозии влияет и геометрические параметры вытяжных металлических труб. Это показало исследование, проведенное нами в вертикальной вытяжной металлической трубе высотой более +180 м, которая находится на производственном объекте химической промышленности Жамбылской области.

Нами произведены замеры толщин стенок этой стальной вытяжной трубы. Измерение толщин стенок стальных труб производили ультразвуковым толщиномером УТ-301 по ГОСТу 28702-90. При измерении использован принцип «эхо», т.е. искатель и приемник совмещены в одном щупе. Возбужденные ультразвуковые сигналы доходят до внутренней поверхности труб и отражаются приемником, зная скорость распространения и время прохождения ультразвука на металле, определили толщину стенок. Результаты замеров приведены в таблице 1.

По результатам замеров установили скорость развития коррозии в стенках вытяжной трубы. Средние показатели результатов замеров показаны в таблице 2 .

\section{Таблица 1}

Результаты замеров толщин стенок вертикальной вытяжной трубы, подверженной коррозией.

\begin{tabular}{|c|c|c|c|c|c|c|}
\hline № & Отметки & $\begin{array}{c}\text { Количество } \\
\text { замеров по разным } \\
\text { сторонам трубы }\end{array}$ & $\begin{array}{c}\text { Проектная } \\
\text { толщина, } \\
\text { мм }\end{array}$ & $\begin{array}{c}\text { Фактическая } \\
\text { толщина, мм }\end{array}$ & $\begin{array}{c}\text { Разница, } \\
\text { мм }\end{array}$ & $\begin{array}{c}\text { Скорость } \\
\text { развития } \\
\text { коррозии, мм/год }\end{array}$ \\
\hline 1 & $+137,616$ & I & 8 & 2,52 & 5,48 & 0,167 \\
\hline 2 & $+137,616$ & II & 8 & 3,56 & 4,44 & 0,135 \\
\hline 3 & $+137,616$ & III & 8 & 3,90 & 4,10 & 0,124 \\
\hline 4 & $+113,616$ & I & 8 & 3,20 & 4,8 & 0,145 \\
\hline 5 & $+113,616$ & II & 8 & 4,03 & 3,97 & 0,120 \\
\hline
\end{tabular}

ISPC Industry \& Technology Europe, 


\begin{tabular}{|l|c|c|c|c|c|c|}
\hline 6 & $+113,616$ & III & 8 & 4,63 & 3,37 & 0,102 \\
\hline \multicolumn{7}{|l|}{$\mid$} \\
\hline 7 & $+81,616$ & I & 8 & 3,90 & 4,1 & 0,120 \\
\hline 8 & $+81,616$ & II & 8 & 5,0 & 3,0 & 0,090 \\
\hline 9 & $+81,616$ & III & 8 & 4,975 & 3,025 & 0,091 \\
\hline \multicolumn{7}{|l|}{} \\
\hline 10 & $+57,616$ & I & 8 & 4,33 & 3,67 & 0,11 \\
\hline 11 & $+57,616$ & II & 8 & 6,43 & 1,57 & 0,040 \\
\hline 12 & $+57,616$ & III & 8 & 5,10 & 2,90 & 0,087 \\
\hline
\end{tabular}

Таблица 2

Средние показатели результатов замеров толщин стенок вертикальной вытяжной трубы, подверженной коррозией.

\begin{tabular}{|c|c|c|c|c|c|}
\hline № & Отметки & $\begin{array}{c}\text { Проектная } \\
\text { толщина, мм }\end{array}$ & $\begin{array}{c}\text { Фактическая } \\
\text { толщина, мм }\end{array}$ & Разница, мм & $\begin{array}{c}\text { Скорость } \\
\text { развития } \\
\text { коррозии, мм/год }\end{array}$ \\
\hline 1 & $+137,616$ & 8 & 3,32 & 4,68 & 0,142 \\
\hline 2 & $+113,616$ & 8 & 3,95 & 4,05 & 0,122 \\
\hline 3 & $+81,616$ & 8 & 4,625 & 3,375 & 0,100 \\
\hline 4 & $+57,616$ & 8 & 5,286 & 2,714 & 0,079 \\
\hline
\end{tabular}

Из замеров видно, что чем выше поднимается вытяжная труба, тем выше увеличивается скорость развития коррозии, а именно коррозия развивается в 2 раза быстрее, чем в нижних участках трубы.

Как выше было отмечено, для развития коррозии на поверхности металлических конструкций должна появиться пленка влаги. При высоких температурах даже появившаяся пленка влаги на вытяжной трубе от дождя быстро испаряется. Так как, в нижних участках вытяжной трубы температура выше из-за интенсивной внутренней теплоотдачи газов, на ней практический не образуется пленка влаги. Соответственно температура нижних участков вытяжной трубы всегда остается выше, чем её окружающая среда $t_{O . C .}<t_{\Gamma T}[10]:$

$$
Q=c m\left(t_{O . C .}-t_{\Gamma T}\right)
$$

где: $Q$ - теплота;

$c$ - теплоемкость;

$m$ - масса вытяжной трубы;

$t_{\Gamma T}$ - температура вытяжной трубы;

$t_{\text {O.C. }}$ - температура окружающей среды.

То есть, на поверхности нижних участков вытяжной трубы влага конденсируется меньше чем в высотных участках, это объясняет, низкую скорость развития коррозии в данных участках.

Что касается высотных участков вытяжной трубы, где интенсивность внутренней теплоотдачи газов уменьшается и возрастает влияние внешних холодных атмосферных слоев, скорость развития коррозии резко увеличивается из-за обильной конденсации влаги на поверхности вытяжной трубы.

\section{References:}

1. Alimbaev BA, Manapbaev BZ, Emenov E (2011) Ob odnom faktore razvitiya atmosfernoy korrozii $\mathrm{v}$ elementakh metallicheskikh konstruktsiy. Materialy respublikanskoy nauchno-prakticheskoy konferentsii «Nauka i sovremennost' - 2011». - Taraz: Taraz universiteti, 2011.- pp. 120-122.
2. Aliev AD, Alimbaev BA, Manapbaev BZ (2015) Sposob zashchity ot atmosfernoy korrozii metallicheskie konstruktsiy // Mat. resp. nauch.-prakt. konf.: «Nauka i sovremennost'-2015». - Taraz: Taraz universiteti, 2015.

3. Alimbayev BA, Manapbayev BZ, Manapbayeva ZZ (2014) Peculiarities of the 
corrosive state of the iron column Iron Pillar in Delhi, India. Theoretical \& Applied Science. «Modern mathematics in Science», Materials of the International Scientific Practical Conference, 30.06.2014, Caracas, Venezuela. №6, $2014 . \quad$ p.31-38. doi: http://dx.doi.org/10.15863/TAS.2014.06.14.6

4. Alimbaev B, Manapbaev BZ (2013) Osobennosti korrozionnogo sostoyaniya deliyskoy zheleznoy kolonny Iron Pillar// Mekhanika i tekhnologii. - Taraz, 2013. - №2. pp. 17-26.

5. Alimbayev BA, Manapbayev BZ, Alimbayeva ZB, Kozhas OO, Rysbai DB (2014) About one way of drawing of the anticorrosive covering on the internal surface of pipes. Theoretical \& Applied Science. «Integration of Science \& Education», Materials of the International Scientific Practical Conference, 30.03.2014, Gothenburg, Sweden. - №3, 2014. pp.24-30. doi:

http://dx.doi.org/10.15863/TAS.2014.03.11.5

6. Alimbayev BA, Manapbayev BZ, Alimbayeva ZB, Djanuzakova RJ (2014) About one mechanism of development of corrosion in steel designs. Theoretical \& Applied Science. «European Research», Materials of the International Scientific Practical Conference, 30.12.2014, Birmingham, United Kingdom. №12, $2014 . \quad$ pp.111-118. doi: http://dx.doi.org/10.15863/TAS.2014.12.20.25

7. Alimbaev BA, Manapbaev BZ (2013) Innovatsionnyy patent RK №27327. Sposob naneseniya antikorrozionnogo pokrytiya na vnutrennyuyu poverkhnost' trub/ Byulleten' №9 RGKP «Natsional'nyy institut intellektual'noy sobstvennosti», Astana.Opubl. 16.09.2013.

8. Alimbaev BA, Manapbaev BZ (2012) Razvitie korrozii $\mathrm{v}$ elementakh metallicheskikh konstruktsiy $\mathrm{v}$ vodnoy srede. - Taraz: Taraz universiteti, 2012.-136.

9. Stromberg AG, Semchenko DP (2001) Fizicheskaya khimiya. Ucheb. dlya khim. spets. vuzov. Pod redaktsiey A.G.Stromberga. - 4-e izd. ispr. - Moscow: Vyssh. shk., 2001. - 527.

10. (1986) Teplotekhnika. Pod obshch. red. V.I. Krutova. - Moscow: Mashinostroenie, 1986. $432 \mathrm{p}$. 